\title{
Modern Glasses at the Science Museum.
}

$\mathrm{A}^{\mathrm{N}}$

Exhibition of Modern Technical and Artistic Glasses at the Science Museum, South Kensing. ton, to remain open until the end of the year, was formally opened on Oct. 21 by Sir Richard Gregory (see Nature, Oct. 24, p. 697). The organisers, who represent the Society of Glass Technology and the Glass Research Delegacy of the University of Sheffield, have endeavoured in this exhibition to illustrate the more striking advances arising from scientific studies in glass technology during the past fifteen years. In doing so, it has been necessary, in view of the limitations of space, to make a selection of the subjects which are comprised within the term "glass technology' and a further choice of material even in those subjects represented. 'Thus, in the main, the problems involved in the manufacture of glasses in modern times which have given rise to many important researches, such as the solution of gases in molten glasses, and the diffusion and flow of viscous liquids at high temperatures, receive no attention, and it has not been found possible to find space for exhibits illustrating researches on raw materials, on the special characteristics of refractory materials required for various manufacturing conditions, and the applications of glasses to the many types of scientific apparatus.

In general, the exhibition may be said to illustrate the relationships between the chemical composition and the physical properties of glasses, with indications of the industrial results of the researches involved. Fourteen sections are employed in classifying the subjects dealt with. Section $A$ comprises a review of the most important literature on glasses (excluding works on optics and optical instruments) which has been published since 1915 . In this collection are the journals of scientific bodies devoted to the study of glasses, trade technical journals, technical books, and works devoted to the historical and artistic side of glasses. Sections $B$ to $E$ are concerned with fundamental properties of glasses ; $F$ to $O$ illustrate how the results of fundamental researches on the relationships between chemical composition and physical properties have been utilised in recent developments in the production of specific types of glasses, the types dealt with including coloured glasses for artistic and utilitarian purposes ; optical, chemical, heat-resisting, illuminating, and electrical glasses; sheet and plate, safety or laminated, and fused silica glasses. Specimens, photographs, and numerous diagrams of data are employed to convey information to the visitor.

It is impossible to do more than refer to a few of the more interesting results of modern work. Section $B$ is devoted to the nature of glass, and illustrates, amongst other matters, the study of the equilibrium diagrams of the complex systems in which glasses fall, and some pretty specimens of crystallisation from glasses are shown. The effect of heat treatment on crystal growth is set out pictorially. A whole case is also devoted to the most modern methods and results of the study of the nature of glasses by the X-ray method. Section $C$ contains many interesting specimens, Roman, medieval, and modern, which have undergone weathering and decay as the result of unsuitable composition; and modern researches which have shown the way to produce very durable glasses are described and illustrated. Section $D$ is devoted to certain physical properties of glasses. Particular attention is paid to modern work on the thermal expansion; and in this sub-section are shown examples of graded glass seals which enable a glass of low thermal expansion to be united to one of high expansion through intermediate joints, and of glass to metal joints. The mechanical properties of glass are illustrated, and types of fracture produced by thermal and mechanical forces are exhibited. The low thermal conductivity of glass is further reduced when drawn into a mass of fibres with intervening air spaces, and British glass 'silk', shown in various forms, is coming into widespread use for heat insulating purposes.

The most spectacular of the sections is $F$, dealing with the colouring and decolourising of glasses. The six cases devoted to this subject stand in the entrance hall of the Museum and at once arrest the eye. The first case starts with some beautiful specimens of coloured Egyptian glasses of the Eighteenth Dynasty. Below them, and extending to the second case, are numerous specimens, specially melted at the Depart. ment of Glass Technology, Sheffield, to illustrate the tremendous range of colouring materials available to the modern glassmaker. More effective illustrations of colouring than these are the specimens of artistic glasses. Three roses, with glass petals of white, pale yellow, and rich red, respectively, simulate the real flowers to a remarkable degree. Amongst the more striking colouring agents in the artistic glass exhibited are selenium (various shades) and the oxides of didymium, neodymium, and praseodymium. The utilitarian division of Section $F$ includes such objects as Crookes glasses, various protecting glasses for furnace workers and welders, signal glass, and colour filters. An offshoot of this section is that devoted to illuminating glasses $(L)$, where 'daylight' lamps and other objects are shown. Also in section $M$ (sheet and plate glasses), reference is made to research on coloured glasses suitable for keeping away flies.

Toughened glass samples appear in Section $L$, and are referred to in Sections $E$ and $J$ also. The nature, methods of manufacture, and sources of defects in ' safety' or laminated glass are well set out in Section $N$. The neighbouring Section $O$ (fused silica) contains a number of historical specimens, as well as others showing that many massive, as well as small, objects of fused silica are now obtainable.

Three cases are devoted to optical glasses and one to optical lens systems. One of the most important advances has been the improvement in transmission both in the ultra-violet and in the infra-red brought about by painstaking efforts to reduce the iron oxide content. A massive specimen shown contains only 55 parts of iron (as $\mathrm{Fe}$ ) per million of glass, and it is claimed that British optical glass is now superior to any other in regard to transmission at both ends of the spectrum.

\section{Foot-and-Mouth Disease Research.*}

THE Fourth Progress Report of the Foot-andMouth Disease Research Committee, just issued, is a record of extremely interesting observations and experiments. We agree with the Committee when it says that "the knowledge of foot-and-mouth disease

* Ministry of Agriculture and Fisheries. Fourth Progress Report of the Foot-and-Mouth Disease Research Committee. Pp. $375+12$ plates. (London: H.M. Stationery Office, 1931.) 7s. $6 d$. net. and the conditions which promote the infection and the means of its prevention have been materially advanced by work in many parts of the world, and that the researchers in this country have taken their fair share in furthering that progress". It is true that we have still no very clear vision of the time when scientific methods of prevention and spread are to be substituted for slaughter. The causal virus is familiar 
and the disease can be produced experimentally with it. Further, it has been clearly demonstrated that with this virus, weakened in various ways, immunity against the disease can be produced. This immunity, however, does not seem to last very long, and until the virus can be grown on artificial media, sufficient of it cannot be obtained to do a very large series of immunisation experiments. The work of Prof. and Mrs. Maitland in Manchester gives us hope of culture, for they have shown quite conclusively that multiplication of the virus will take place in the presence of living embryo tissue of guinea-pigs. This is a decided advance.

Further evidence is given in the Report of the different types of the virus, but the most encouraging fact in relation to treatment, especially serological treatment, is that 92 per cent of the strains obtained from outbreaks in Great Britain belong to the $O$ type. If, therefore, we were able to obtain an anti-virus of this type, we could deal hopefully with almost all the cases that occur.

Much valuable information has been collected on the survival of the virus in sewage, in milk, in carcases after storage at different temperatures, and of its resistance to pickling, etc. In administrative work these results should prove of great importance. Again, the infection of rabbits, hedgehogs, and rats opens up a suggestive field for investigation of the method of spread. In 1924, I reported to the Committee the results of experiments by myself and colleagues which showed that rats could be infected with the disease, confirmed this by further reports in 1928, and suggested that the rat, by its migratory habits, might be a carrier. The infection in rats has now been fully confirmed by the Committee, and in a note on the origin of fresh outbreaks it is stated that "the discovery of very inconspicuous signs of the disease in rats must increase the care with which symptoms of infection in these animals are sought, and add fresh importance to the warfare waged against these animals ". To the farmer and dairyman this possible carriage is of the utmost importance.

The whole Report is full of interest, and the scientific workers under the Committee are to be congratulated. All their work is leading to the goal of prevention.
J. M. Beattie.

\section{Cotton Growing in Egypt.}

$D^{\mathrm{H}}$ W. L. BALLS and his assistants in the Botanical Section of the Egyptian Ministry of Agrieulture have published within recent years two bulletins on the "Operation of the Seed Control Law upon the Pedigree of Cotton Seed".* The first is a survey of the effect of the control during the first two years, and the second includes the first and extends the period to four growing years from 1926 until 1930 . Egypt supplies the bulk of cotton for the fine spinning industry, in which quality is of great importance, and competition with lustrous fabrics made from synthetic fibres is making the use of good quality cotton more and more essential.

It would appear that the maintenance of the purity of good strain cottons is desirable for both the farmer in Egypt and the spinner in England, and that little difficulty should be met in operating a law designed to help in securing plentiful supplies of high quality pedigree stocks. Unfortunately, the tests applied by the botanical staff show that as the law becomes better known, methods of evasion are discovered and practised. Cotton seed is used both for growing and crushing, and it is this dual purpose which leads to malpractices. The law has improved commercial stocks with commendable rapidity, and the method of evaluating the improvement, and incidentally of detecting evasions, is surprisingly simple. There exists in Egypt a low quality cotton, known as Hindi, which is very easily recognised when growing and also in seed form. The percentage of Hindi seed has been found to be a very good index of the amount of contamination in seed stocks. A simple count is all that is required, and the method of plotting these counts shows very vividly how the law is operating.

The curves in these publications are so easily interpreted that it is possible to obtain from them the maximum allowable Hindi-content from year to year, although the legal limit has been reduced yearly to alvery low percentage. There can be little doubt that deliberate adjustment of the Hindi-content to fall with the legal limit is being practised, but if mixing could be kept within the limit the purpose of the law would be fulfilled.

* Ministry of Agriculture, Egypt : Technical and Scientific Service. Bulletin No. 85: The Operation of the Seed Control Law upon the Pedigree of Cotton Seed in Seasons 1926-27 and 1927-28. By Dr. W. Lawrence Balls and Armenag Eff. Bedevian. Pp. 61+27 plates. 5 P.T. Bulletin No. 100: Developments of the Existing System for Seed Supply of Cotton in Egypt. By Dr. W. Lawrence Ralls. Pp. $11+3$ plates, 5 P.T. Bulletin No. 104: The Operation of the Seed Control Law upon the Pedigree of Cotton Seed in Season 1926 to 1930 , with a Discussion of Evasions of the Law. By Dr. W. Lawrence Balls and Armenag Eff. Bedevian. Pp. $28+23$ plates. 10 P.T. (Cairo Government Press, 1920-1931.)
There are many cases where the Hindi-content is well above the limit, and the system of analysis employed is searching enough to locate the lawbreakers with scientific if not legal conviction. It seems that the offenders can only be made to mend their ways if the penalties for evasion are as carefully regulated as the system of diagnosing the culprits. While the Hindi-content is a simple and reliable index of either careless or deliberate lowering of the standard of purity of the seed stocks, it is not a true index of the purity of the cotton types, as natural crossing and other deteriorating influences are unavoidable in large scale cultivation.

The botanical staff clearly recognises that the most effective way of cleaning commercial stocks is by renewal of seed from clean stocks, and the methods adopted to achieve this are given in a bulletin entitled "Developments of the Existing System for Seed Supply of Cotton in Egypt".* Perhaps the most interesting technical item in this publication is the use of large cages of high light-transparency made of fine 'staybrite' steel wire, for the propagation of pure types. The mesh is fine enough to prevent natural crossing, and improvement in the design and production of these cages has advanced to the stage when the cost per unit area covered is little more than the cost of the pre-War cages made of corrodible wire.

The raising of sufficient seed from such small eage stocks to supply the extensive growing areas of Egypt is a story in itself, and the scientific organisation of the expansion process leads us almost to accept the statement that the botany of the cotton plant is better known than that of any other plant. It might be contended that the method of seed renewal is adequate for the maintenance of clean stocks, and that the pruning effect of the seed control law is antithetical. Assuming it is possible to provide adequate seed supplies from reliable sources at one or two years' remove, accident or carelessness will lead to premature contamination, but if all concerned in the handling of the stocks are compelled by rigorously enforced law to exercise necessary care to prevent mixing, the burden of seed renewal will be lightened. Pruning and seed renewal are thus complementary, and all who have an interest in the prosperity of the cotton industry will wish success to the botanical and agronomic sections in Egypt in their efforts to improve by both means the quality and uniformity of cotton seed stocks.
F. P. Slater. 